\title{
Répercussions de la révision de la LA
}

\section{Roman Fried}

Correspondance:

Dr Roman Fried

Association pour le contrôle

de qualité médical

Institut de chimie clinique

Hôpital universitaire de Zurich

CH-8091 Zurich

roman.fried@usz.ch

\section{Exemple $\mathbf{n}^{\circ} 1$ (Prix en francs)}

\begin{tabular}{|c|c|c|c|c|}
\hline Position LA & Analyse & $\begin{array}{l}\text { Actuellement } \\
\text { Au laboratoire du } \\
\text { cabinet médical }\end{array}$ & $\begin{array}{l}\text { Dès juillet } 2009 \\
\text { Au laboratoire du } \\
\text { cabinet médical }\end{array}$ & $\begin{array}{l}\text { Au laboratoire } \\
\text { industriel }\end{array}$ \\
\hline 1245.00 & CRP & 20.70 & - & 10.00 \\
\hline 8270.00 & Hémogramme III & 18.00 & - & 10.00 \\
\hline 8579.00 & Status urinaire & 14.40 & 20.00 & - \\
\hline 4700.00 & $\begin{array}{l}\text { Taxe pour } \\
\text { mandat externe }\end{array}$ & - & - & 24.00 \\
\hline 4707.00 & Taxe de présence & - & 4.00 & - \\
\hline 4707.10 & $\begin{array}{l}\text { Supplément pour } \\
\text { le suffixe } C\end{array}$ & - & 2.00 & - \\
\hline 4708.00 & $\begin{array}{l}\text { Supplément } \\
\text { transitoire }\end{array}$ & - & 1.00 & 1.00 \\
\hline $\begin{array}{l}\text { Total par } \\
\text { laboratoire }\end{array}$ & & 53.10 & 27.00 & 45.00 \\
\hline $\begin{array}{l}\text { Total pour } \\
\text { le patient }\end{array}$ & & 53.10 & $72.00(+35,6 \%)$ & \\
\hline
\end{tabular}

Exemple $\mathbf{n}^{\circ} \mathbf{2}$ (Prix en francs)

\begin{tabular}{|c|c|c|c|c|}
\hline Position LA & Analyse & $\begin{array}{l}\text { Actuellement } \\
\text { Au laboratoire du } \\
\text { cabinet médical }\end{array}$ & $\begin{array}{l}\text { Dès juillet } 2009 \\
\text { Au laboratoire du } \\
\text { cabinet médical }\end{array}$ & $\begin{array}{l}\text { Au laboratoire } \\
\text { industriel }\end{array}$ \\
\hline 8270.00 & Hémogramme III & 18.00 & - & 10.00 \\
\hline 4700.00 & $\begin{array}{l}\text { Taxe pour mandat } \\
\text { externe }\end{array}$ & - & - & 24.00 \\
\hline 4707.00 & Taxe de présence & - & - & - \\
\hline 4707.10 & $\begin{array}{l}\text { Supplément pour } \\
\text { le suffixe } C\end{array}$ & - & - & - \\
\hline 4708.00 & $\begin{array}{l}\text { Supplément } \\
\text { transitoire }\end{array}$ & - & - & 1.00 \\
\hline $\begin{array}{l}\text { Total par } \\
\text { laboratoire }\end{array}$ & & 18.00 & - & 35.00 \\
\hline $\begin{array}{l}\text { Total pour } \\
\text { le patient }\end{array}$ & & 18.00 & $35.00(+94,4 \%)$ & \\
\hline
\end{tabular}

L'Office fédéral de la santé publique (OFSP) a effectué ses calculs en partant du principe que la structure et l'offre des laboratoires de cabinet médical n'évoluent pas en Suisse, ce qui est illusoire. Depuis 2001, le chiffre d'affaires de ces laboratoires a été déjà baissé à deux reprises, au total de 19\%. L'OFSP prévoit que la nouvelle liste des analyses entraînera une nouvelle baisse d'env.
$20 \%$ et vise, pour l'ensemble des laboratoires, des économies à hauteur de 100 millions à court terme, voire de 200 millions à plus long terme.

Selon l'évolution de la situation, le système compliqué de taxes et de suppléments prévu dans le domaine des soins de base pourrait occasionner une forte augmentation des coûts pour les patients.

\section{Taxes et suppléments}

Selon une étude sur les laboratoires de cabinets médicaux de Suisse, ceux-ci exécutent par an 10 millions de mandats correspondant à 40 millions d'analyses.

Compte tenu des données 2007 de la Caisse des médecins, nous estimons que 30 millions d'analyses présentent le suffixe $C$ et que 10 millions d'analyses portent un autre suffixe. 7,5 millions de francs sont déduits pour env. 1 million de mandats.

\begin{tabular}{|c|c|c|c|}
\hline \multicolumn{2}{|c|}{ Position LA } & \multirow{2}{*}{$\begin{array}{l}\text { Nombre } \\
10 \text { mio }\end{array}$} & \multirow{2}{*}{$\begin{array}{l}\text { Montant } \\
\text { en francs } \\
40 \text { mio }\end{array}$} \\
\hline 4707.00 & Taxe de présence & & \\
\hline 4707.10 & $\begin{array}{l}\text { Supplément } \\
\text { pour le suffixe C }\end{array}$ & 30 mio & 60 mio \\
\hline 4707.20 & $\begin{array}{l}\text { Supplément pour } \\
\text { d'autres suffixes }\end{array}$ & 10 mio & 10 mio \\
\hline 4708.00 & $\begin{array}{l}\text { Supplément } \\
\text { transitoire }\end{array}$ & 40 mio & 40 mio \\
\hline \multirow[t]{2}{*}{$x x x x \cdot x x$} & $\begin{array}{l}\text { Déduction pour } \\
\text { cause de limita- } \\
\text { tion: } 24 \text { francs }\end{array}$ & $1 \mathrm{mio}$ & 7,5 mio \\
\hline & Total & & 142,5 mio \\
\hline
\end{tabular}

\section{Scénarios pour le futur}

Pour l'heure, seuls 10 à $20 \%$ des mandats exigent des analyses supplémentaires externes dans un laboratoire industriel grâce au bon équipement des laboratoires de praticien. Un démantèlement de ces laboratoires augmentera la part de ces analyses externes.

Quelles en seront les conséquences pour les patients? La taxe 4700.00 de 24 francs sera facturée pour chaque mandat externe, ce qui correspond à un supplément de 240 millions de francs par an pour 10 millions de mandats. 